\title{
A quantitative kinetic model for the fast and isothermal hydrothermal liquefaction of Nannochloropsis sp.
}

\author{
David C. Hietala ${ }^{a}$, Julia L. Faeth ${ }^{a}$, Phillip E. Savage $e^{a, b, *}$ \\ ${ }^{a}$ Department of Chemical Engineering, University of Michigan, 2300 Hayward Street, 3074 H.H. Dow Building, Ann Arbor, Michigan 48109, \\ United States \\ ${ }^{b}$ Department of Chemical Engineering, The Pennsylvania State University, 160 Fenske Lab, University Park, Pennsylvania 16802, United States
}

\begin{abstract}
Hydrothermal liquefaction (HTL) is a technology for converting algal biomass into biocrude oil and high-value products. To elucidate the underlying kinetics for this process, we conducted isothermal and non-isothermal reactions over a broad range of holding times $(10 \mathrm{~s}-60 \mathrm{~min})$, temperatures $\left(100-400{ }^{\circ} \mathrm{C}\right)$, and average heating rates $\left(110-350{ }^{\circ} \mathrm{C} \mathrm{min}^{-1}\right)$. Biocrude reached high yields ( $\geq 37 \mathrm{wt} \%$ ) within $2 \mathrm{~min}$ for heat-source set-point temperatures of $350{ }^{\circ} \mathrm{C}$ or higher. We developed a microalgal HTL kinetic model valid from $10 \mathrm{~s}-60 \mathrm{~min}$, including significantly shorter timescales (10 s $-10 \mathrm{~min}$ ) than any previous model. The model predicts that up to $46 \mathrm{wt} \%$ biocrude yields are achievable at $400{ }^{\circ} \mathrm{C}$ and 1 min, reaffirming the utility of short holding times and "fast" HTL. We highlight potential trade-offs between maximizing biocrude quantity and facilitating aqueous phase recovery, which may improve biocrude quality.
\end{abstract}

Keywords: Hydrothermal liquefaction, microalgae, kinetic model, temperature profile

\section{Introduction}

Producing energy-dense fuels from biomass is a compelling strategy for reducing transportation-related $\mathrm{CO}_{2}$ emissions because such fuels recycle carbon from the atmosphere via photosynthesis, rather than introduce ancient carbon from fossil resources. Moreover, microalgae have garnered considerable interest as biomass feedstocks because of their high photosynthetic efficiency, fast growth rate relative to terrestrial biomass, ability to be cultivated on non-arable land and thus avoiding competition with agriculture, and capability to convert solar energy into energy-dense compounds like lipids (Brennan and Owende, 2010). The energy required to convert algal biomass to biofuel precursors can exceed the heating value of the biomass if the processing necessitates drying prior to conversion. Hydrothermal liquefaction (HTL) is a process that uses high-temperature, high-pressure water to directly convert wet biomass to an energy-dense biocrude oil (Dote et al., 1994; Brown et al., 2010), obviating most of the

\footnotetext{
${ }^{*}$ Corresponding author. Tel.: +1-814-867-5876; fax: +1-814-865-7846

Email addresses: hietala@umich.edu (David C. Hietala), psavage@psu.edu (Phillip E. Savage)
} 
energy penalties incurred by drying. Moreover, HTL also produces aqueous-phase and gaseous fractions as co-products.

Numerous studies have examined the effects of temperature and holding time on the product distribution created by isothermal HTL of microalgae (Jena et al., 2011; Garcia Alba et al., 2012; Valdez et al., 2012; Christensen et al., 2014). These studies all concluded that temperature has a much greater effect on product distribution than holding time; however the holding times employed were long (10 - $120 \mathrm{~min})$ and reactions were generally quenched well after most algal solids had reacted to form products at temperatures relevant to $\mathrm{HTL}\left(T \geq 250{ }^{\circ} \mathrm{C}\right)$.

Compared to prior work on isothermal HTL, far fewer studies have examined non-isothermal HTL with rapid heating (fast HTL). Faeth et al. (2013) used average heating rates of $170-350{ }^{\circ} \mathrm{C} \min ^{-1}$ and obtained comparable or higher biocrude yields than from isothermal conditions but over much shorter timescales ( $1-5 \mathrm{~min})$. The results suggest that microalgal HTL occurs on timescales much shorter than previously thought. Others have demonstrated similar results for fast HTL in batch reactors of corn stover (Zhang et al., 2008), bacteria and yeast (Valdez et al., 2014), and macroalgae (Bach et al., 2014), and for continuous HTL of microalgae $\left(200-990{ }^{\circ} \mathrm{C} \mathrm{min}{ }^{-1}\right)\left(\mathrm{Jazrawi}^{\mathrm{a}}\right.$ et al., 2013; Biller et al., 2015). Moreover, very recently Cheng et al. (2016) developed a glass- and silicon-based chip to achieve even more rapid heating rates $\left(\sim 900^{\circ} \mathrm{C} \mathrm{min}^{-1}\right)$. They observed appreciable biocrude formation $(38$ $\%$ of maximum fluorescence intensity) at $1 \mathrm{~min}$ for at set-point temperature of $300{ }^{\circ} \mathrm{C}$, further demonstrating the short timescales of algal HTL kinetics.

Despite this recent shift toward shorter holding times (1 - 5 min) (Faeth et al., 2013; Jazrawi et al., 2013; Biller et al., 2015; Cheng et al., 2016), the field currently lacks a comprehensive examination of HTL product fraction evolution with respect to time, temperature, and heating rate over timescales short enough to elucidate reaction kinetics. This gap in the literature presents an opportunity to explore these process variables in a more systematic manner. Additionally, few attempts have been made to quantitatively model microalgal HTL kinetics. There have been several attempts to model HTL product distribution at specific isothermal HTL conditions based on the biochemical composition of the microalgae (Biller and Ross, 2011; Teri et al., 2014; Leow et al., 2015), but none of those models attempt to predict kinetic behavior. Valdez and Savage (2013) developed a reaction network and posited the first kinetic model for the (isothermal) HTL of Nannochloropsis sp., a marine species of microalgae, encompassing a wide range of temperatures $\left(250-400{ }^{\circ} \mathrm{C}\right)$ and holding times $(10-90 \mathrm{~min})$. This model successfully correlated the yields of solid, biocrude, aqueous-phase, and gas products for the reaction conditions within the scope of the study. However, the data used to develop the model only included experiments with holding times of 10 min or longer, with no data at low solids conversion and little variation in product distribution by $20 \mathrm{~min}$. This restriction on reaction times was imposed such that all reactions operated under predominantly isothermal conditions (reactor heat-up contributed to $\leq 50 \%$ of the holding time).

It is essential that a microalgal HTL kinetic model incorporates data collected on the same timescale over which 
reactions occur and that the actual temperature profile experienced inside the reactor is known if the heat-up time is comparable to the holding time. In this study, we sought to conduct the most thorough investigation of the coupled effects of time, temperature, and heating rate on HTL product yields to date. We then used this expansive database to develop a modified reaction network and quantitative kinetic model to calculate HTL product yields over a broad range of temperatures $\left(200-400{ }^{\circ} \mathrm{C}\right)$, holding times $(10 \mathrm{~s}-60 \mathrm{~min})$, and average heating rates $(110-350$ $\left.{ }^{\circ} \mathrm{C} \min ^{-1}\right)$. This is the first kinetic model for fast HTL.

\section{Materials and Methods}

\subsection{Experimental}

A preservative-free slurry of $31 \pm 1$ wt \% (s.d.) Nannochloropsis sp. and water was purchased from Reed Mariculture, who reported its composition to be $59 \mathrm{wt} \%$ proteins, $14 \mathrm{wt} \%$ lipids, and $20 \mathrm{wt} \%$ carbohydrates. The ash content was previously reported to be $6 \mathrm{wt} \%$ (Faeth et al., 2013). We constructed $1.67 \mathrm{~mL}$ batch reactors from a $3 / 8$ in. Swagelok ${ }^{\circledR}$ port connector and two caps, all of 316 stainless-steel construction. We loaded each reactor with enough algae slurry $(0.309-0.589 \mathrm{~g})$ and deionized water $(0.353-0.673 \mathrm{~g})$ to constitute a $15 \mathrm{wt} \%$ slurry of algae in water. We calculated reactor loadings such that reactor pressures would not exceed 400 bar at the final temperature. After loading, reactors were sealed to $45 \mathrm{ft}$-lbs. using a torque wrench.

Additional $1.50 \mathrm{~mL}$ proxy reactors for temperature measurements were constructed using a ${ }^{3} / 8$ in. port connector, a cap, and a bored-through reducing union (reducing the internal diameter from ${ }^{3} / 8$ in. to $1 / 8$ in.). An Omega Engineering, Inc. ${ }^{1} / 8$-in.-diameter 18 -in.-long stainless-steel-clad K-type thermocouple was inserted into the $1 / 8$-in. end of the reducing union such that the tip of the thermocouple resided in the middle of the reactor body when closed. We loaded each proxy reactor with enough deionized water to match approximately the total density in the HTL reactors. An Omega Engineering, Inc. UWBT-TC-UST-NA Datalogger recorded the temperature measured by the thermocouples in the proxy reactors every $0.1 \mathrm{~s}$.

The loaded, sealed reactors were submerged in a Techne IFB-51 fluidized sand bath preheated to the specified set-point temperature. We define holding time as the time from the instant the reactor begins to heat up to the instant the reactor starts to cool down. At the end of the holding time, reactors were removed from the fluidized sand bath and quickly quenched in cold water. After about 3 min, the exterior of the reactors was dried with paper towels. For reactions with holding times less than 1 min, we placed proxy reactors in the sand bath simultaneously with the reaction vessels, and for all other reactions $(t>1 \mathrm{~min})$ we used temperature profiles previously recorded at the same set-point temperature, averaged over at least two independent trials. Typically, reactors immersed at set-point temperatures of $200,300,400,500$, and $600{ }^{\circ} \mathrm{C}$ exhibited average heating rates of $110,170,230,290$, and 350 ${ }^{\circ} \mathrm{C} \mathrm{min}^{-1}$, respectively. These heating rates were calculated as linear averages over the time it took reactors to reach within $95 \%$ of the maximum temperature change, typically about 95 s. For example, this threshold for a 300 
${ }^{\circ} \mathrm{C}$ set-point temperature would occur when the temperature is about $286{ }^{\circ} \mathrm{C}(0.95=(286-25) /(300-25))$. Representative temperature profiles are listed in Table A.1 in Appendix A.

Within $2 \mathrm{~h}$ after quenching and drying, reactors were weighed, tapped forcefully on the benchtop three times, opened to release gases, and weighed again. We calculated the mass of gas evolved as the difference between these two reactor masses. Biocrude, aqueous-phase, and solid products were recovered according to the procedure described previously (Valdez et al., 2012). This procedure involves pouring the reactor contents into a glass conical centrifuge tube, rinsing the reactor with $9 \mathrm{~mL}$ of dichloromethane (>95\% optima grade, Fisher Scientific) in small aliquots, and collecting these rinsings in the same glass tube. This tube was then mixed using a vortex mixer and centrifuged to facilitate phase separation.

Following centrifugation, the organic (dichloromethane-soluble) phase was manually collected using a pipette and transferred to a pre-weighed glass tube. The remaining aqueous phase and solid products were again mixed using a vortex mixer and centrifuged. The aqueous phase was transferred to a pre-weighed vial via pipette and the residual solids were left in the original glass tube. Tubes containing the dichloromethane-dissolved organics, remaining solids, and wet aqueous phase were each dried under nitrogen (99.998 \%, Metro Welding Supply Corp.), using a Labconco $^{\circledR}$ RapidVap ${ }^{\circledR}$ Vertex ${ }^{\mathrm{TM}}$ Dry Evaporator with a solid aluminum heating block at 35,35 , and $70{ }^{\circ} \mathrm{C}$, respectively, and weighed until two consecutive cycles of drying and weighing produced tube masses varying by $<2$ mg. The dried organic, solid, and aqueous phases are what we term the biocrude, solid, and aqueous-phase products, respectively. Furthermore, we define the volatiles fraction to be the compounds primarily dissolved in the aqueous phase but lost due to evaporation upon drying at $70{ }^{\circ} \mathrm{C}$ (Valdez et al., 2012). We also report the sum of the aqueous-phase and volatile product fractions, which is an estimate of the total material in the aqueous phase immediately post HTL (Jena et al., 2011). Product yields were calculated by dividing the mass of product collected by the initial mass of dry algae for a given reaction. The yield of volatiles was calculated by difference. In a few cases we observed gas yields that were higher than expected based on other data collected under similar reaction conditions. In these rare cases we used interpolation to estimate the gas yields. For some reactions conducted below

$250{ }^{\circ} \mathrm{C}$, the insolubility of unreacted algae in dichloromethane made it difficult to recover all of the material. In these cases we scaled the solid and aqueous-phase product yields to close the mass balance. Details about the procedure used for adjustment along with both the unadjusted and adjusted yields appear in Appendix A.

\section{Results and Discussion}

This section reports the product yields from HTL of Nannochloropsis sp. at temperatures of $100-400{ }^{\circ} \mathrm{C}$, holding times of $10 \mathrm{~s}-60 \mathrm{~min}$, and average heating rates of $110-350{ }^{\circ} \mathrm{C} \mathrm{min}^{-1}$. Following the experimental results, we propose a reaction network and kinetic model. 


\subsection{Product fraction yields}

Figure 1 depicts the yields of product fraction $i\left(x_{i}\right)$ from HTL of Nannochloropsis sp. The black lines on the plots represent typical reactor temperature profiles resulting from set-point temperatures of $200,300,400$, and $500{ }^{\circ} \mathrm{C}$. Each individual point represents a single HTL reaction shaded to show the product fraction yield and plotted at the holding time and final reactor temperature reached. Table A.2 in Appendix A lists the exact product yields used in Figure 1.

Figure 1a depicts solid yields. To the best of our knowledge, this is the first study to capture the shift from low conversion $(<30 \%)$ at short holding times $(t<1 \mathrm{~min})$ and low temperatures $\left(T<250{ }^{\circ} \mathrm{C}\right)$ to high conversion $(\sim 100$ $\%)$ at typical isothermal HTL conditions $\left(t>20 \mathrm{~min}, T>300^{\circ} \mathrm{C}\right)$. As expected, solid yields are highest at short holding times and low temperatures (bottom left) and lowest at long holding times and high temperatures (top right). Solid yields decrease monotonically with increasing reaction severity throughout the entire range of HTL reaction conditions examined until a lower bound (on the order of the ash content) is reached. At a set-point temperature of $300^{\circ} \mathrm{C}$, for example, this lower bound is observed for $t>3 \mathrm{~min}$, and this time decreases with increasing temperature. At $t>3 \mathrm{~min}$, and $T=200^{\circ} \mathrm{C}$, solid product yields decrease with increasing holding times, though complete conversion is not observed within the range of reaction times examined at this temperature. Above $200{ }^{\circ} \mathrm{C}$, solids yields decrease dramatically with increasing temperature; moreover, solids conversion at $200{ }^{\circ} \mathrm{C}$ is remarkably slower than at $250^{\circ} \mathrm{C}$, compared to other $50^{\circ} \mathrm{C}$ increments (e.g. $250^{\circ} \mathrm{C}$ compared to $300^{\circ} \mathrm{C}$ ). This may indicate that hydrolysis of algal biomolecules becomes much more kinetically favorable in the range of $200-250{ }^{\circ} \mathrm{C}$, which is consistent with temperatures reported in the literature (Sasaki et al., 2000; Rogalinski et al., 2008; Garcia Alba et al., 2012).

Figure $1 \mathrm{~b}$ displays biocrude yields. The trends in biocrude yield were of comparable magnitude and opposite to those of solid yields, with yields generally increasing as a function of temperature and time. At short holding times, a maximum yield was reached at around $300-400^{\circ} \mathrm{C}$ and $3-7 \mathrm{~min}$. At longer times characteristic of isothermal HTL, this maximum yield shifts to a lower range of $250-350^{\circ} \mathrm{C}$, with little variation in yields after $5 \mathrm{~min}$. This temperature range for maximizing biocrude yield and these trends are in agreement with myriad studies for isothermal HTL (Biller and Ross, 2012; Valdez et al., 2012; Eboibi et al., 2014; Christensen et al., 2014; Sudasinghe et al., 2015). At $400{ }^{\circ} \mathrm{C}$, biocrude yields show a slight, yet non-negligible decrease with increasing reaction time. Decreasing biocrude yields with increasing time at temperatures above $350{ }^{\circ} \mathrm{C}$ has also been observed previously (Jena et al., 2011; Valdez et al., 2012).

Figure 1c shows that gas yields generally increase with increasing temperature and time. Although the trend at long reaction times is consistent with previous studies (Jena et al., 2011; Garcia Alba et al., 2012; Valdez et al., 2012; Christensen et al., 2014), the gas yields in the present work are higher than those reported previously for Nannochloropsis sp. (Valdez et al., 2012) but on the same magnitude as those for other microalgae (Jena et al., 2011; 
Garcia Alba et al., 2012). This difference in observed gas product yields may be a consequence of measurement technique. In this study, we measured the mass of gas evolved shortly after the reaction by the difference in mass of vented and unvented reactors, however Valdez et al. (2012) employed reactors equipped with gas valves to measure gas by GC analysis. We took care to ensure that the mass of gas evolved was measured within $2 \mathrm{~h}$ after reactions were quenched to limit the extent that carbon dioxide, the principal component of the gas phase (Brown et al., 2010; Jena et al., 2011; Garcia Alba et al., 2012), dissolves in the aqueous phase. The dissolution kinetics of carbon dioxide from the gas phase into the aqueous phase are fast, with a forward rate constant of $1 \times 10^{10} \mathrm{~s}^{-1}$ (Stumm and Morgan, 1996). However, diffusion of dissolved carbon dioxide in water is slow, with a diffusion coefficient of $\mathcal{D}=$ $2.233 \times 10^{-9} \mathrm{~m}^{2} / \mathrm{s}$ (Cadogan et al., 2014). Our analysis shows that $<25 \%$ of the carbon dioxide would have dissolved in the aqueous phase within $2 \mathrm{~h}$ of time between quenching a reaction and gas measurement. Moreover, we agitated the reactors by forcefully tapping them on the benchtop three times before opening to further liberate carbon dioxide back into the gas phase. See Appendix A for an extensive analysis of this phenomenon.

Figure $1 \mathrm{~d}$ depicts aqueous-phase product yields. At every set-point temperature except $200{ }^{\circ} \mathrm{C}$, aqueous-phase product yields increase initially to a maximum value at moderate reaction severity, then decrease at high reaction severity. At short times, they reach a maximum at about $320-380{ }^{\circ} \mathrm{C}$ and $45 \mathrm{~s}-2 \mathrm{~min}$. We postulate that rapid heating $\left(175-375{ }^{\circ} \mathrm{C} \min ^{-1}\right)$ could be facilitating protein and amino acid recovery in the aqueous phase.

Garcia-Moscoso et al. (2015) developed a similar, yet more rapid process they refer to as flash hydrolysis (240 - 320 ${ }^{\circ} \mathrm{C}, 6-12 \mathrm{~s}$ ) with essentially instantaneous heating achieved by mixing pre-heated, pressurized water with algal slurry in a continuous reaction system. These conditions allowed peptides and arginine, among other protein-derived co-products, to be readily recovered while simultaneously preserving the lipid content of the algal solids. Rapidly heating reaction mixtures to elevated temperatures seems to favor protein-derived product recovery in the aqueous-phase while also apparently minimizing cross-reactions between lipids and protein (Garcia-Moscoso et al., 2015).

At longer times and isothermal conditions, aqueous-phase product yields monotonically decrease with increasing temperature and reaction time (for set-point temperatures above $200{ }^{\circ} \mathrm{C}$ only), reaching a minimum at $400{ }^{\circ} \mathrm{C}$ and $40 \mathrm{~min}$ and a maximum at $200{ }^{\circ} \mathrm{C}$ and $40 \mathrm{~min}$. These trends are consistent with those reported previously for yields of aqueous-phase products (Jena et al., 2011; Garcia Alba et al., 2012; Valdez et al., 2012; Christensen et al., 2014). Moreover, a number of recent studies have explored low-temperature $\left(125-225^{\circ} \mathrm{C}\right)$ pre-treatment steps, usually as a means of reducing the nitrogen content of the algal solids thereby improving the quality of the resulting biocrude oil produced from a subsequent HTL reaction (Miao et al., 2012; Costanzo et al., 2015; Jazrawi et al., 2015) or transesterification reaction (Levine et al., 2013; Lu et al., 2015) while simultaneously producing a nutrient-enriched aqueous phase. In terms of the solid and aqueous-phase product yields, our results at $200{ }^{\circ} \mathrm{C}$ are consistent with the findings of those studies. Moreover, Costanzo et al. (2015) and Jazrawi et al. (2015) showed that reactions responsible for nitrogen recovery in the aqueous phase are acid catalyzed with rates that increase with reaction 
severity.

Figure 1e illustrates the volatile product yields. Volatile yields are essentially zero for $T<250{ }^{\circ} \mathrm{C}$, and very low at short holding times $(t<2 \mathrm{~min})$. At high reaction severity, volatile yields increase substantially, especially at $T \geq 350$ ${ }^{\circ} \mathrm{C}$ and $t \geq 2 \mathrm{~min}$. These values for volatile yields and the aforementioned trends are consistent with those reported by Valdez et al. (2012) and Christensen et al. (2014) (through the difference between their mass recovery and unity in the latter case). Moreover, these trends are nearly equal and opposite of those for aqueous-phase products, suggesting that aqueous-phase components are degrading to form smaller, more volatile compounds in this region. The aqueous phase was dried at $70{ }^{\circ} \mathrm{C}$, and it is likely that some of these compounds become volatile in the range of $25<T<70$ ${ }^{\circ} \mathrm{C}$. Increases in volatile yields also occur simultaneously with small decreases in biocrude at high reaction temperature $\left(T \geq 300{ }^{\circ} \mathrm{C}\right)$ and long reaction times $(t \geq 40 \mathrm{~min})$. These concurrent phenomena suggest that aqueous-phase product degradation is the primary reaction pathway to produce volatiles, but that some degradation of biocrude at elevated temperatures and long reaction times cannot be ruled out.

Given the results in Figures 1d and 1e, along with previous studies indicating that volatile products are produced primarily from aqueous-phase products (Valdez et al., 2012), we also plot aqueous-phase product and volatile yields combined in Figure 1f. The trends for the combined volatile and aqueous-phase products match those of just the aqueous-phase products in Figure 1d at low reaction severity and those of the volatiles in Figure 1e at high reaction severity. Some experiments at extended holding time $(t \geq 20 \mathrm{~min})$ show decreased volatile and aqueous-phase product yields and increased gas yields, suggesting that gasification of aqueous-phase products occurs at those conditions. We expect these values to show more variability than the other products because, like volatile yields, these values were calculated by difference rather than by direct measurement.

\subsection{Kinetic model development}

We sought to derive a reaction network and develop a corresponding kinetic model that accurately describes the behavior of microalgal HTL over the entire range of reaction conditions employed. We began with the kinetic model and associated reaction network developed by Valdez and Savage (2013), which was corroborated both by isothermal algal HTL reactions (Valdez et al., 2012) and additional isothermal reactions of the individual product fractions (solid, biocrude, and aqueous-phase products) (Valdez and Savage, 2013). Using their model to predict the results discussed in Section 3.1 resulted in the parity plots shown in Figure A.1. This model reasonably calculates biocrude yields from HTL at the conditions employed in that study (Fig. A.1b), although the aqueous-phase and volatile product yields were over-calculated and gas yields were under-calculated, likely due to the differences in gas quantification discussed in Section 3.1. However, the model breaks down $(\sigma=17 \mathrm{wt} \%)$ at holding times shorter than 10 min (Fig. A.1a), clearly demonstrating the need for a model that describes fast HTL.

In general, the results discussed in Section 3.1 support the reaction network developed by Valdez and Savage (2013). The exception is that our results do not immediately suggest that a biocrude to gas pathway exists. Given that small 
but appreciable gas formation occurs at low reaction severity conditions, where no biocrude is present, we instead employ a direct solids to gas pathway instead of biocrude to gas. Moreover we add an aqueous-product to volatile pathway to describe that transition shown in Figures 1d and 1e. Figure 2 presents this modified reaction network with pathways that lead to biocrude (B), aqueous-phase product (A), gas (G), and volatile (V) formation from algal solids (S). We assume each reaction pathway in Figure 2 to be psuedo-first-order and follow Arrhenius kinetics:

$$
k_{i j}(t)=A_{i j} \exp \left(\frac{-E_{i j}}{R T(t)}\right)
$$

Here, $k_{i j}(t)$ is the rate constant for the reaction pathway from reactant $i$ to product fraction $j, A_{i j}$ is the pre-exponential factor, $E_{i j}$ is the activation energy, $R$ is the gas constant, and $T(t)$ is the temperature, which is time-dependent during the non-isothermal part of each experiment. Applying Equation 1 and the batch reactor design equation to the reaction network in Figure 2 yields the following system of first-order ordinary differential equations for the temporal evolution of the product fraction yields, $x_{i}$ :

$$
\begin{aligned}
\frac{d x_{S}^{*}}{d t} & =-\left(k_{S B}+k_{S A}+k_{S G}\right) x_{S}^{*} \\
\frac{d x_{B}}{d t} & =k_{S B} x_{S}^{*}+k_{A B} x_{A}^{*}-k_{B A} x_{B} \\
\frac{d x_{G}}{d t} & =k_{S G} x_{S}^{*}+k_{A G} x_{A}^{*} \\
\frac{d x_{A}^{*}}{d t} & =k_{S A} x_{S}^{*}+k_{B A} x_{B}-\left(k_{A B}+k_{A G}+k_{A V}\right) x_{A}^{*} \\
\frac{d x_{V}}{d t} & =k_{A V} x_{A}^{*}
\end{aligned}
$$

Given that solids and aqueous-phase product yields approach steady nonzero values at the highest reaction severities explored herein, we also employed the following change of variables:

$$
\begin{aligned}
& x_{S}=x_{S}^{\infty}+x_{S}^{*} \\
& x_{A}=x_{A}^{\infty}+x_{A}^{*}
\end{aligned}
$$

$x_{S}$ and $x_{A}$ are measured directly (Figure 1a and 1d, respectively) and we calculated $x_{S}^{\infty}=4 \pm 1 \mathrm{wt} \%$ and $x_{A}^{\infty}=12 \pm 4$ wt $\%$ based on the average values of $x_{S}$ and $x_{A}$ for all experiments above $300{ }^{\circ} \mathrm{C}$ with holding times longer than 8 $\min . x_{S}^{\infty}$ represents the average amount of unreacted (primarily ash) and repolymerized solids remaining at high reaction severity, and our reported value is consistent with reported solid yields in the literature for HTL of Desmodesmus sp. (Garcia Alba et al., 2012), Nannochloropsis sp. (Valdez et al., 2012), Phaeodactylum tricornutum (Christensen et al., 2014), and Spirulina platensis (Jena et al., 2011) at these conditions. $x_{A}^{\infty}$ represents the average amount of aqueous-phase compounds remaining at high reaction severity, and our reported value is consistent with reported aqueous-phase product yields for Desmodesmus sp. (Garcia Alba et al., 2012) at these conditions (also dried at $70{ }^{\circ} \mathrm{C}$ ). Incorporating $x_{S}^{\infty}$ and $x_{A}^{\infty}$ in the model ensured that it would always calculate reasonable yields for those product fractions. 
We performed three control experiments, following the same procedure outlined in Section 2 at room temperature $\left(25^{\circ} \mathrm{C}\right)$ and a holding time of $60 \mathrm{~min}$, to determine the initial condition for the model to be $x_{S, 0}=84 \pm 2 \mathrm{wt} \%$ $\left(x_{S, 0}^{*}=80 \pm 3 \mathrm{wt} \%\right), x_{A, 0}=15 \pm 2 \mathrm{wt} \%\left(x_{A, 0}^{*}=3 \pm 4 \mathrm{wt} \%\right), x_{B, 0}=1 \pm 0 \mathrm{wt} \%, x_{G, 0}=0 \mathrm{wt} \%$, and $x_{V, 0}=0 \mathrm{wt} \%$. Using the temperature profiles and product yield data from each experiment, we calculated values for all kinetic parameters by simultaneously solving the system of first-order, ordinary differential equations in MATLAB ${ }^{\circledR}$ with the function ode23s. We then used lsqnonlin to minimize the objective function, which consisted of a 45 (experiment) by 5 (product) matrix of differences between the observed and calculated weight fractions. Confidence intervals for parameters were calculated using the function nlparci.

\subsection{Kinetic model results}

Table 1 displays the Arrhenius parameters for the chemical reaction pathways, with confidence intervals representing the standard deviation. These parameters are valid on the temperature, holding-time, and average-heating-rate ranges of $100-400{ }^{\circ} \mathrm{C}, 10 \mathrm{~s}-60 \mathrm{~min}$, and $110-350{ }^{\circ} \mathrm{C} \mathrm{min}^{-1}$, respectively.

The activation energies for the solids conversion pathways $(S \rightarrow B, S \rightarrow A$, and $S \rightarrow G$ ) are comparable to those reported for the hydrolysis of various compounds in high-temperature water, including proteins to amino acids (46 $\left.191 \mathrm{~kJ} \mathrm{~mol}^{-1}\right)$ and acylglycerides to free fatty acids $\left(50-105 \mathrm{~kJ} \mathrm{~mol}^{-1}\right)($ Changi et al., 2015). The values are lower than those reported for carbohydrate conversion, including cellulose, starch, and mono- and disaccharides (92 - 164 $\mathrm{kJ} \mathrm{mol}^{-1}$ ) (Changi et al., 2015), perhaps because carbohydrates constituted just $20 \mathrm{wt} \%$ of the initial biomass. Moreover, carbohydrate conversion has been demonstrated to be slower than the conversion of proteins and lipids (Biller and Ross, 2011; Teri et al., 2014). The activation energies in Table 1 for gas formation pathways ( $S \rightarrow G$ and $A \rightarrow G)$ are comparable to those reported by Guan et al. (2012) for hydrothermal gasification of algae, when the reported rate constants for individual gaseous species are lumped together (Valdez and Savage, 2013). In general, our model features pre-exponential factors and activation energies higher than those reported by Valdez and Savage (2013). This translates to calculated values for $k_{S B}$ and $k_{S A}$ that are about an order of magnitude higher than those calculated using the Valdez and Savage (2013) model.

Figure 3a shows the instantaneous selectivity, $S_{S j}=k_{S j} / k_{S, T}$, of solids conversion reactions $S \rightarrow j$, where $j=A, B, G$, with respect to temperature. Here $k_{S, T}=k_{S A}+k_{S B}+k_{S G}$ is the total rate constant for disappearance of solids. The selectivities of solids to aqueous-phase products and biocrude decrease and increase monotonically, respectively, with increasing reaction temperature, with the rate of biocrude formation from solids exceeding that of aqueous-phase product formation at around $275^{\circ} \mathrm{C}$. This trend suggests that rapidly heating the reaction mixture to $275^{\circ} \mathrm{C}$ or higher would maximize biocrude production from algal solids.

Figure $3 \mathrm{~b}$ depicts the instantaneous selectivity, $S_{A j}=k_{A j} / k_{A, T}$, of aqueous-phase product conversion reactions $A \rightarrow j$, where $j=B, G, V$, with respect to temperature. Here $k_{A, T}=k_{A B}+k_{A G}+k_{A V}$ is the total rate constant of 
disappearance of aqueous-phase products. The selectivity of aqueous-phase products to biocrude follows that of aqueous-phase products to gas closely throughout the entire range of temperatures plotted, although biocrude is slightly favored below $170{ }^{\circ} \mathrm{C}$, and gas is slightly favored for $170-270{ }^{\circ} \mathrm{C}$. The selectivity of volatile product formation, $S_{A V}$, increases substantially with reaction temperature, rendering volatiles the favored product fraction above $270{ }^{\circ} \mathrm{C}$.

Figure 4 depicts observed product fraction yields and model solutions calculated using representative temperature profiles for each set-point temperature. Several data also show standard deviations obtained from replicate reactions (dotted lines); these experimental uncertainties are comparable to those reported by Valdez and Savage (2013) and Faeth et al. (2013). Figures $4 \mathrm{~d}$ and $4 \mathrm{e}$ show that the model correlates the data very well at set-point temperatures of 350 and $400{ }^{\circ} \mathrm{C}$, respectively. The model solutions at 250 and $300{ }^{\circ} \mathrm{C}$ (Fig. $4 \mathrm{~b}$ and $4 \mathrm{c}$, respectively) are generally good, with the exception of an over-prediction of aqueous-phase product yields at intermediate holding times. Model calculations for solid, biocrude, and gas yields remain well correlated in this region, however. The model exhibits the lowest accuracy in Figure 4a for a set-point temperature of $200{ }^{\circ} \mathrm{C}$. Here, the model under-predicts solid yields (over-predicts conversion) and correspondingly over-predicts aqueous-phase product, biocrude, and gas yields.

One possible explanation for the reduced accuracy in Fig. $4 \mathrm{a}$ and $4 \mathrm{~b}$ is that the non-homogeneity of the algal slurry causes the reaction mixture to deviate from pseudo-first-order and/or Arrhenius kinetics behavior, with the cell walls potentially imposing an energy threshold for liberating the intracellular components of the algae. Garcia Alba et al. (2012) examined SEM images of the solids product fraction before and after conducting hydrothermal liquefaction of Desmodesmus sp. at temperatures in the range of $200-275^{\circ} \mathrm{C}$. They found that there were significant morphological differences in the solids fraction in this region, with major degradation observed between 225 and $250{ }^{\circ} \mathrm{C}(\mathrm{Garcia}$ Alba et al., 2012). The reduced model accuracy at $T_{s p} \leq 250{ }^{\circ} \mathrm{C}$ and the results presented by Garcia Alba et al. (2012) demonstrate that further studies of hydrothermal conversion at low temperatures of microalgae with different types of cell walls may be required to improve model accuracy in that region. In general, however, the quality of the agreement between observed and calculated product yields at $T_{s p} \geq 300{ }^{\circ} \mathrm{C}$ demonstrates the utility of the present kinetic parameters and reaction network at calculating yields for both non-isothermal and isothermal HTL conditions.

Figure A.2 shows residual plots for each product fraction. The model over-calculates solid yields (Fig. A.2a) at moderate reaction severity; above $280^{\circ} \mathrm{C}$ the residuals are significantly smaller. The residual plots highlight that, at low to moderate reaction severity $\left(T<280^{\circ} \mathrm{C}, 20 \mathrm{~s}<t<3 \mathrm{~min}\right)$, the model tends to deviate from observed product fraction yields by a larger magnitude than at moderate to high reaction severity, with the exception of volatile yields. This observation reaffirms a need for future studies to further elucidate reaction kinetics in this low-to-moderate severity region.

Figure 5 depicts parity plots of the observed and calculated biocrude yields, for several previous studies (Biller and Ross, 2011; Valdez et al., 2012; Faeth et al., 2013; López Barreiro et al., 2013; Leow et al., 2015). The specific data 
points that were selected appear in Table A.3 in Appendix A. We chose data within the scope of our model limits, including experiments conducted at $400{ }^{\circ} \mathrm{C}$ or lower for microalgae of the genus Nannochloropsis. Moreover, due to limited availability of temperature profile information, we assumed an isothermal temperature for data from the López Barreiro et al. (2013), Biller and Ross (2011), and Leow et al. (2015) studies and assumed temperature profiles typical for this study for data from the Faeth et al. (2013) and Valdez et al. (2012) studies. The standard deviation was 5 wt \%, which is comparable to the experimental uncertainties shown in Figure 4 and demonstrated in studies with a similar experimental procedure (Valdez and Savage, 2013; Faeth et al., 2013). Figure 5 demonstrates that the model can be successfully applied for biocrude prediction to microalgae within the Nannochloropsis genus and of a similar biochemical composition over a broad range of reaction conditions. Comparison of model-predicted yields to literature data for other products is much less meaningful, due to differences in experimental procedures. See Appendix A for further explanation on model validation for other product fractions.

\subsection{Calculated yields}

With the establishment of a kinetic model that can describe algal HTL as a function of temperature and time, irrespective of heating rate, we now use it to improve our understanding of the kinetics that govern this process. Figure 6 depicts density plots of product fraction yields as functions of temperature and time for isothermal HTL. Dashed lines correspond to the maximum aqueous-phase product $\left(x_{A}^{\max }\right)$ and biocrude $\left(x_{B}^{\max }\right)$ yields achievable as a function of isothermal HTL temperature.

Figure 6a illustrates the change in the calculated solids yields, $x_{S}^{\text {calc }}$, over time for different temperatures. At short times $(t<30 \mathrm{~s})$ and low temperature $\left(T<250^{\circ} \mathrm{C}\right)$, little solids conversion occurs. Beyond this region, solids react readily with increasing temperature and time, and complete solids conversion can be achieved for all temperatures examined. The curve for the maximum aqueous-phase product yield, $x_{A}^{\max }$, coincides with the region where the solids completely disappear (i.e., $x_{S}^{c a l c} \approx x_{S}^{\infty}$ ), which seems reasonable if the algal solids are the main producers of aqueous-phase products. Moreover, the curve for the maximum biocrude yield, $x_{B}^{\max }$, always occurs well beyond the point of solids depletion, indicating that secondary reactions contribute significantly to biocrude production.

Figure $6 \mathrm{~b}$ shows the calculated biocrude yields. Biocrude formation increases substantially with reaction temperature at short times, coinciding with the corresponding decrease in solids (Fig. 6a). Biocrude yields as high as $46 \mathrm{wt} \%$ are achievable after $1 \mathrm{~min}$ at $400{ }^{\circ} \mathrm{C}$. Once solids completely disappear, the biocrude yield is much less sensitive to reaction severity. This trend of little variation also holds over a fairly wide region of temperature and times, but shifts downward with increasing reaction time, from a range of $325-400{ }^{\circ} \mathrm{C}$ at 1 min to a range of $225-350{ }^{\circ} \mathrm{C}$ at 60 min, for example. In general, the biocrude yield increases with reaction severity, but the existence of maxima indicates that it does decrease at elevated temperatures $\left(T>350{ }^{\circ} \mathrm{C}\right)$ and long reaction times $(t>20 \mathrm{~min})$. At times of $10-60 \mathrm{~min}$, these maximum yields occur between $300-350{ }^{\circ} \mathrm{C}$. This range of temperatures is in excellent agreement with numerous previous studies conducted under isothermal conditions for various microalgae, including 
$375{ }^{\circ} \mathrm{C}$ for Desmodesmus sp. (Garcia Alba et al., 2012), $300-350{ }^{\circ} \mathrm{C}$ for Nannochloropsis sp. (Brown et al., 2010; Valdez et al., 2012), $350{ }^{\circ} \mathrm{C}$ for Phaeodactylum tricornutum (Christensen et al., 2014), and $350{ }^{\circ} \mathrm{C}$ for Spirulina platensis (Jena et al., 2011). The maximum biocrude yield ranged only from $45-46$ wt \% regardless of temperature $\left(T \geq 300{ }^{\circ} \mathrm{C}\right)$. This modest variation is within the uncertainty in the data, and it indicates that HTL is a very robust process in that it can achieve nearly the same maximum biocrude yields over a very wide range of temperatures and times. This robustness may provide opportunities to select HTL conditions that provide high biocrude yields and also optimize some other desired outcome (e.g. biocrude quality, nitrogen recovery in the aqueous phase, etc.).

Figure $6 \mathrm{c}$ displays gas yields, $x_{G}^{c a l c}$, calculated over time for several temperature profiles. Gas yields are fairly low at low reaction severity, but increase with increasing temperature and time beyond the point of solids depletion (Fig. 6a). At longer reaction times $(t>30 \mathrm{~min})$, gas formation is favored at moderate temperatures $\left(250-350{ }^{\circ} \mathrm{C}\right)$. The global maximum calculated gas yield of $20 \mathrm{wt} \%$ occurs at $T=280{ }^{\circ} \mathrm{C}$ and $t=60 \mathrm{~min}$.

Figure $6 \mathrm{~d}$ depicts the calculated yields of aqueous-phase products, $x_{A}^{\text {calc }}$. At low reaction severity, aqueous-phase product yields increase significantly with increasing temperature and time until solids are depleted and then decrease with further increases in reaction severity. Moreover, the maximum aqueous-phase product yield itself, $x_{A}^{\max }$, decreases monotonically with increasing temperature, from a global maximum of $52 \mathrm{wt} \%$ at $T=200{ }^{\circ} \mathrm{C}$ and $t=50$ $\min$, to $35 \mathrm{wt} \%$ at $T=400{ }^{\circ} \mathrm{C}$ and $t=10 \mathrm{~s}$. Notably, the temperature range that maximum aqueous-phase products are produced at long times is consistent with those reported in the literature, including $225-250{ }^{\circ} \mathrm{C}$ for Desmodesmus sp. (Garcia Alba et al., 2012), $250{ }^{\circ} \mathrm{C}$ for Nannochloropsis sp. (Valdez et al., 2012), and $200{ }^{\circ} \mathrm{C}$ for Spirulina platensis (Jena et al., 2011). Similar to $x_{A}^{\max }$ occurring at the point of solids depletion (Fig. 6a), the maximum biocrude yield, $x_{B}^{\max }$, always occurs when the yield of aqueous-phase products reaches approximately 20 wt $\%$ or less.

Figure 6e shows $x_{V}^{\text {calc }}$, the calculated volatile yields. At short times, volatile formation only occurs at $T>300{ }^{\circ} \mathrm{C}$, increasing rapidly in the range of $350-450{ }^{\circ} \mathrm{C}$. At longer times, volatile yields become appreciable only at $T>275$ ${ }^{\circ} \mathrm{C}$. Similarly to gas yields, the volatiles yield increases monotonically with increasing reaction time, due to the irreversibility imposed by the reaction network in Figure 2. The global maximum is 44 wt $\%$ at $T=400{ }^{\circ} \mathrm{C}$ and $t=$ $60 \mathrm{~min}$, the most severe reaction condition shown. Volatiles are also the most favored product at elevated temperatures $\left(T>350{ }^{\circ} \mathrm{C}\right)$, given the high values of the Arrhenius parameters for the rate constant for the $A \rightarrow V$ reaction pathway. For completeness, we also show aqueous-phase and volatile product yields together in Figure $6 \mathrm{f}$.

Examined together, the plots in Figure 6 illustrate that one can decouple effects of temperature and time on the HTL product distribution. Above $250{ }^{\circ} \mathrm{C}$ and $30 \mathrm{~s}$, biocrude and aqueous-phase product yields increase dramatically with increasing reaction severity until solids are depleted. Aqueous-phase product yields reach a maximum at that region and decrease with increasing reaction severity while biocrude yields increase modestly and volatile yields become appreciable. At extreme reaction severities, biocrude yields begin to decrease modestly and volatile yields increase 
substantially. Examination of longer reaction times in Figure 6 shows that temperature plays a larger role than time in determining product distribution; aqueous-phase products, biocrude and gas (collectively), and volatiles are favored below $225^{\circ} \mathrm{C}$, between $225-350{ }^{\circ} \mathrm{C}$, and above $350{ }^{\circ} \mathrm{C}$, respectively.

Examining Figure 6 also demonstrates an interplay between aqueous-phase products and biocrude. For a given reaction time, the maximum biocrude yield generally occurs at temperatures about $100{ }^{\circ} \mathrm{C}$ higher than the maximum aqueous-phase product yield. As previously discussed, the increase in biocrude yield observed between $x_{A}^{\max }$ and $x_{B}^{\max }$ can be entirely attributed to aqueous-phase products reacting to from dichloromethane-soluble products (biocrude) because solids are essentially depleted in that region $\left(x_{S}^{\text {calc }}\right.$ is of order $\left.x_{S}^{\infty}\right)$. Aqueous-phase products are rich in nitrogen, and it has been demonstrated that nitrogen incorporation in the biocrude increases with reaction time and temperature in this range (Jena et al., 2011; Garcia Alba et al., 2012; Valdez et al., 2012; Faeth et al., 2013; Jazrawi et al., 2013; Cheng et al., 2016). Therefore, it seems plausible that this increase in biocrude yield with holding time is the result of nitrogen-containing aqueous-phase compounds reacting to become less polar or incorporating themselves with larger organic molecules through mechanisms like the Maillard reaction (Tian et al., 2014; Teri et al., 2014; Changi et al., 2015). We speculate that maximizing aqueous-phase product formation either through short reaction times and rapid heating or longer reaction times at lower temperatures $\left(200-225^{\circ} \mathrm{C}\right)$ may be desirable from a biocrude quality and energy input standpoint. Doing so may lower nitrogen incorporation into the biocrude (and maximize nitrogen recovery into the aqueous phase for recycling), reducing the burden of downstream catalytic hydrodenitrogenation reactions necessary for biocrude refinement (Tian et al., 2014).

\section{Conclusions}

We elucidated algal HTL kinetics through a comprehensive study of the coupled effects of temperature, reaction time, and heating rate on algal HTL product yields. We used these data to develop a reaction network and kinetic model valid over a broad range of holding times (10 s - $60 \mathrm{~min})$, including much shorter timescales (10 s - $10 \mathrm{~min})$ than previously established. Calculated yields correlate well with observed yields, and the model shows that biocrude yields as high as $46 \mathrm{wt} \%$ are achievable at $400{ }^{\circ} \mathrm{C}$ and $1 \mathrm{~min}$. The model highlights potential trade-offs between biocrude quantity and quality.

\section{Acknowledgements}

Catherine Griffith provided experimental assistance. The University of Michigan College of Engineering and the National Science Foundation (Grant EFRI 1332342) provided financial support. Julia Faeth acknowledges that this material is based on work supported by the National Science Foundation Graduate Student Research Fellowship under Grant DGE 1256260. 


\section{References}

1. Bach, Q.V., Sillero, M.V., Tran, K.Q., Skjermo, J., 2014. Fast hydrothermal liquefaction of a Norwegian macro-alga: Screening tests. Algal Research 6, 271-276.

2. Biller, P., Ross, A., 2011. Potential yields and properties of oil from the hydrothermal liquefaction of microalgae with different biochemical content. Bioresource Technology 102, 215-225.

3. Biller, P., Ross, A.B., 2012. Hydrothermal processing of algal biomass for the production of biofuels and chemicals. Biofuels 3, 603-623.

4. Biller, P., Sharma, B.K., Kunwar, B., Ross, A.B., 2015. Hydroprocessing of bio-crude from continuous hydrothermal liquefaction of microalgae. Fuel 159, 197-205.

5. Brennan, L., Owende, P., 2010. Biofuels from microalgae - A review of technologies for production, processing, and extractions of biofuels and co-products. Renewable and Sustainable Energy Reviews 14, 557-577.

6. Brown, T.M., Duan, P., Savage, P.E., 2010. Hydrothermal Liquefaction and Gasification of Nannochloropsis sp. Energy \& Fuels 24, $3639-3646$.

7. Cadogan, S.P., Maitland, G.C., Trusler, J.P.M., 2014. Diffusion Coefficients of CO 2 and N 2 in Water at Temperatures between 298.15 K and 423.15 K at Pressures up to $45 \mathrm{MPa}$. Journal of Chemical \& Engineering Data 59, 519-525.

8. Changi, S.M., Faeth, J.L., Mo, N., Savage, P.E., 2015. Hydrothermal Reactions of Biomolecules Relevant for Microalgae Liquefaction. Industrial \& Engineering Chemistry Research 54, 11733-11758.

9. Cheng, X., Ooms, M.D., Sinton, D., 2016. Biomass-to-biocrude on a chip via hydrothermal liquefaction of algae. Lab Chip 16, $256-260$.

10. Christensen, P.S., Peng, G., Vogel, F., Iversen, B.B., 2014. Hydrothermal Liquefaction of the Microalgae Phaeodactylum tricornutum : Impact of Reaction Conditions on Product and Elemental Distribution. Energy \& Fuels 28, 5792-5803.

11. Costanzo, W., Jena, U., Hilten, R., Das, K., Kastner, J.R., 2015. Low temperature hydrothermal pretreatment of algae to reduce nitrogen heteroatoms and generate nutrient recycle streams. Algal Research 12, 377-387.

12. Dote, Y., Sawayama, S., Inoue, S., Minowa, T., Yokoyama, S.y., 1994. Recovery of liquid fuel from hydrocarbon-rich microalgae by thermochemical liquefaction. Fuel 73, 1855-1857.

13. Eboibi, B., Lewis, D., Ashman, P., Chinnasamy, S., 2014. Effect of operating conditions on yield and quality of biocrude during hydrothermal liquefaction of halophytic microalga Tetraselmis sp. Bioresource Technology 170, 20-29.

14. Faeth, J.L., Valdez, P.J., Savage, P.E., 2013. Fast Hydrothermal Liquefaction of Nannochloropsis sp. To Produce Biocrude. Energy \& Fuels 27 , 1391-1398.

15. Garcia Alba, L., Torri, C., Samorì, C., van der Spek, J., Fabbri, D., Kersten, S.R.A., Brilman, D.W.F.W., 2012. Hydrothermal Treatment (HTT) of Microalgae: Evaluation of the Process As Conversion Method in an Algae Biorefinery Concept. Energy \& Fuels 26, 642-657.

16. Garcia-Moscoso, J.L., Teymouri, A., Kumar, S., 2015. Kinetics of Peptides and Arginine Production from Microalgae (Scenedesmus sp.) by Flash Hydrolysis. Industrial \& Engineering Chemistry Research 54, 2048-2058.

17. Guan, Q., Wei, C., Savage, P.E., 2012. Kinetic model for supercritical water gasification of algae. Physical Chemistry Chemical Physics 14, 3140 .

18. Jazrawi, C., Biller, P., He, Y., Montoya, A., Ross, A.B., Maschmeyer, T., Haynes, B.S., 2015. Two-stage hydrothermal liquefaction of a high-protein microalga. Algal Research 8, 15-22. 
19. Jazrawi, C., Biller, P., Ross, A.B., Montoya, A., Maschmeyer, T., Haynes, B.S., 2013. Pilot plant testing of continuous hydrothermal liquefaction of microalgae. Algal Research 2, 268-277.

20. Jena, U., Das, K., Kastner, J., 2011. Effect of operating conditions of thermochemical liquefaction on biocrude production from Spirulina platensis. Bioresource Technology 102, 6221-6229.

21. Leow, S., Witter, J.R., Vardon, D.R., Sharma, B.K., Guest, J.S., Strathmann, T.J., 2015. Prediction of microalgae hydrothermal liquefaction products from feedstock biochemical composition. Green Chem. 17, 3584-3599.

22. Levine, R.B., Bollas, A., Savage, P.E., 2013. Process improvements for the supercritical in situ transesterification of carbonized algal biomass. Bioresource Technology 136, 556-564.

23. López Barreiro, D., Zamalloa, C., Boon, N., Vyverman, W., Ronsse, F., Brilman, W., Prins, W., 2013. Influence of strain-specific parameters on hydrothermal liquefaction of microalgae. Bioresource Technology 146, 463-471.

24. Lu, Y., Levine, R.B., Savage, P.E., 2015. Fatty Acids for Nutraceuticals and Biofuels from Hydrothermal Carbonization of Microalgae. Industrial \& Engineering Chemistry Research 54, 4066-4071.

25. Miao, C., Chakraborty, M., Chen, S., 2012. Impact of reaction conditions on the simultaneous production of polysaccharides and bio-oil from heterotrophically grown Chlorella sorokiniana by a unique sequential hydrothermal liquefaction process. Bioresource Technology 110 , $617-627$.

26. Rogalinski, T., Liu, K., Albrecht, T., Brunner, G., 2008. Hydrolysis kinetics of biopolymers in subcritical water. The Journal of Supercritical Fluids 46, 335-341.

27. Sasaki, M., Fang, Z., Fukushima, Y., Adschiri, T., Arai, K., 2000. Dissolution and Hydrolysis of Cellulose in Subcritical and Supercritical Water. Industrial \& Engineering Chemistry Research 39, 2883-2890.

28. Stumm, W., Morgan, J.J., 1996. Aquatic chemistry: chemical equilibria and rates in natural waters. Wiley.

29. Sudasinghe, N., Reddy, H., Csakan, N., Deng, S., Lammers, P., Schaub, T., 2015. Temperature-Dependent Lipid Conversion and Nonlipid Composition of Microalgal Hydrothermal Liquefaction Oils Monitored by Fourier Transform Ion Cyclotron Resonance Mass Spectrometry. Bioenergy Research 8, 1962-1972.

30. Teri, G., Luo, L., Savage, P.E., 2014. Hydrothermal Treatment of Protein, Polysaccharide, and Lipids Alone and in Mixtures. Energy \& Fuels 28, 7501-7509.

31. Tian, C., Li, B., Liu, Z., Zhang, Y., Lu, H., 2014. Hydrothermal liquefaction for algal biorefinery: A critical review. Renewable and Sustainable Energy Reviews 38, 933-950.

32. Valdez, P.J., Nelson, M.C., Faeth, J.L., Wang, H.Y., Lin, X.N., Savage, P.E., 2014. Hydrothermal Liquefaction of Bacteria and Yeast Monocultures. Energy \& Fuels 28, 67-75.

33. Valdez, P.J., Nelson, M.C., Wang, H.Y., Lin, X.N., Savage, P.E., 2012. Hydrothermal liquefaction of Nannochloropsis sp.: Systematic study of process variables and analysis of the product fractions. Biomass and Bioenergy 46, 317-331.

34. Valdez, P.J., Savage, P.E., 2013. A reaction network for the hydrothermal liquefaction of Nannochloropsis sp. Algal Research 2, $416-425$.

35. Zhang, B., von Keitz, M., Valentas, K., 2008. Thermal Effects on Hydrothermal Biomass Liquefaction. Applied Biochemistry and Biotechnology $147,143-150$. 


\begin{tabular}{ccc}
\hline Pathway & $\log (\mathrm{A})\left[\log \left(\mathrm{s}^{-1}\right)\right]$ & $E_{a}\left[\mathrm{~kJ} \mathrm{~mol}^{-1}\right]$ \\
\hline $\mathrm{S} \rightarrow \mathrm{B}$ & $5.0 \pm 0.6$ & $74 \pm 6$ \\
$\mathrm{~S} \rightarrow \mathrm{A}$ & $4.0 \pm 0.5$ & $65 \pm 6$ \\
$\mathrm{~S} \rightarrow \mathrm{G}$ & $3.9 \pm 0.7$ & $68 \pm 8$ \\
$\mathrm{~B} \rightarrow \mathrm{A}$ & $3.8 \pm 1.0$ & $99 \pm 19$ \\
$\mathrm{~A} \rightarrow \mathrm{B}$ & $1.7 \pm 0.5$ & $59 \pm 8$ \\
$\mathrm{~A} \rightarrow \mathrm{G}$ & $2.3 \pm 0.5$ & $64 \pm 7$ \\
$\mathrm{~A} \rightarrow \mathrm{V}$ & $7.6 \pm 1.5$ & $119 \pm 17$ \\
\hline
\end{tabular}

Table 1: Arrhenius parameters for reaction pathways in Figure 2. 


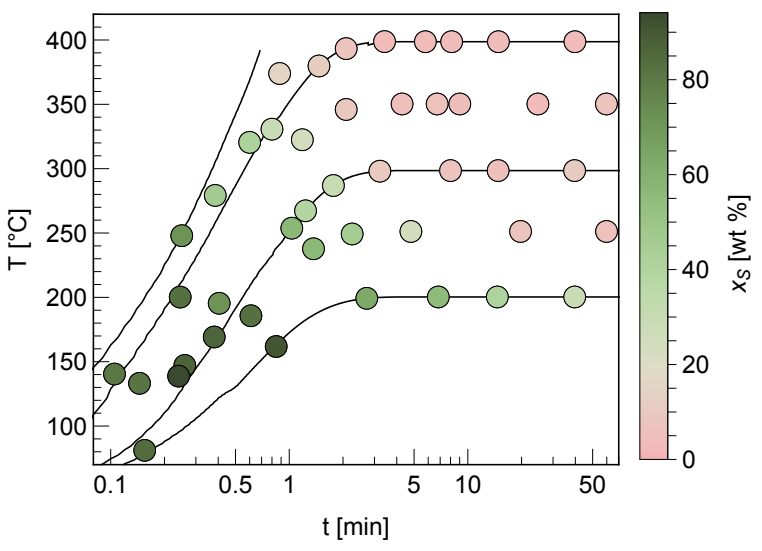

(a) Solid

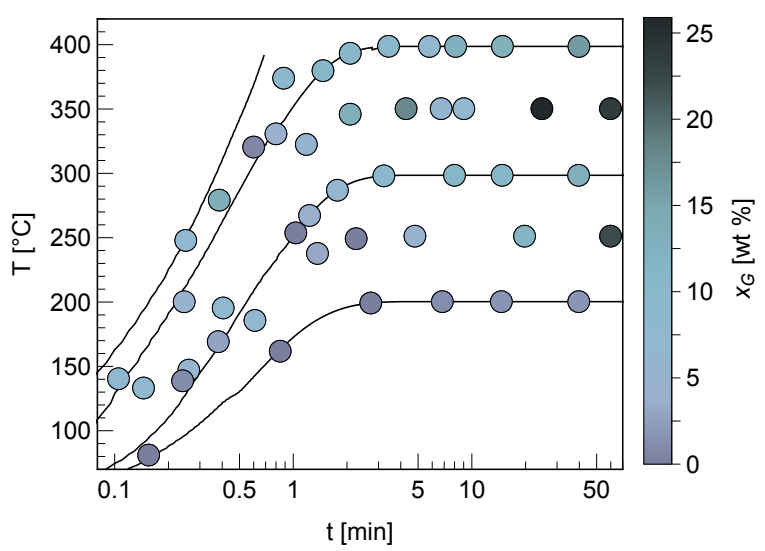

(c) Gas

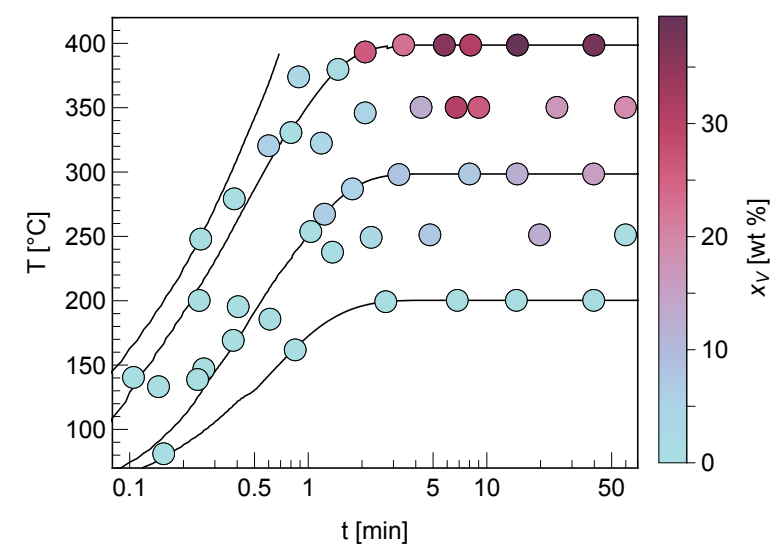

(e) Volatile products

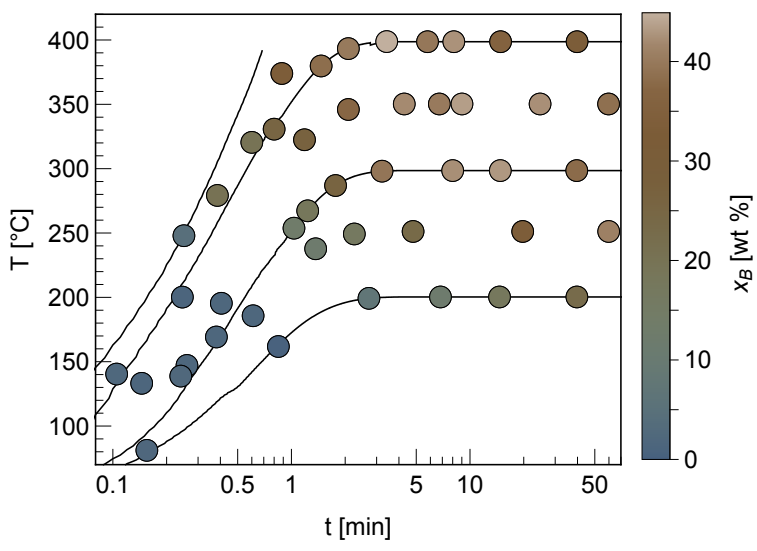

(b) Biocrude

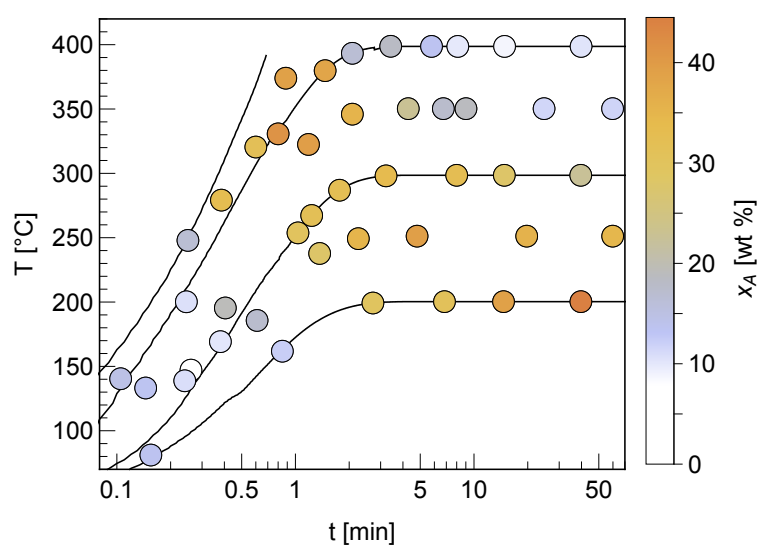

(d) Aqueous-phase products

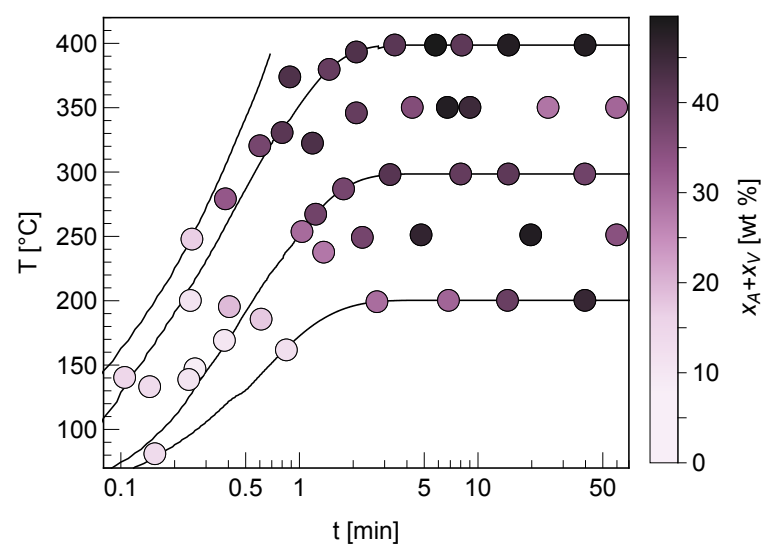

(f) Aqueous-phase and volatile products

Figure 1: Product fraction yields from the hydrothermal liquefaction of Nannochloropsis sp. plotted as functions of final reactor temperature and holding time. Solid lines represent typical temperature profiles based on sand-bath set-point temperatures of $200,300,400$, and $500{ }^{\circ} \mathrm{C}$. 


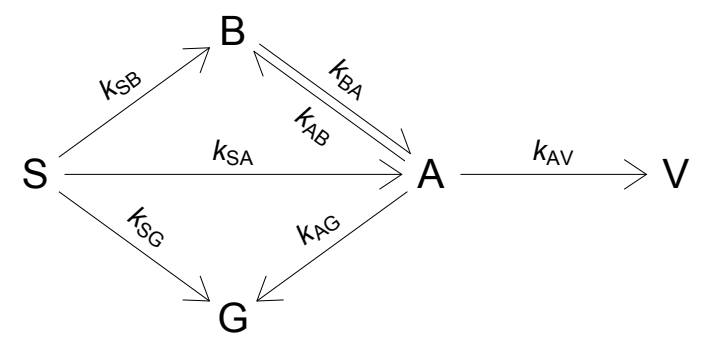

Figure 2: Reaction network for the fast and isothermal hydrothermal liquefaction of Nannochloropsis sp. S, B, A, G, and V represent solids, biocrude, aqueous-phase products, gases, and volatiles, respectively. 

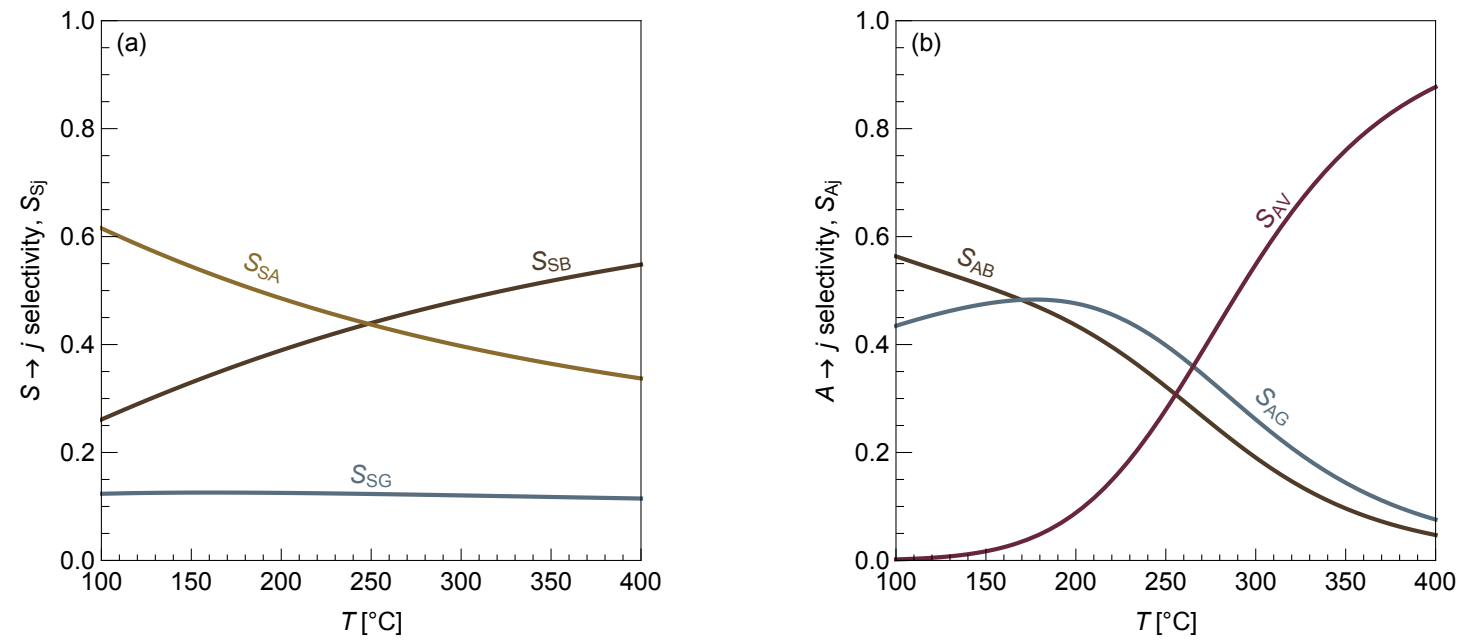

Figure 3: (a) Instantaneous solids conversion selectivities, $S_{S j}=k_{S j} / k_{S, T}$, where $k_{S, T}=k_{S B}+k_{S A}+k_{S G}$, with respect to temperature. Dark gold, brown, and gray-blue lines correspond to aqueous-phase products (A), biocrude (B), and gas (G), respectively. (b) Instantaneous aqueous-phase product conversion selectivities, $S_{A j}=k_{A j} / k_{A, T}$, where $k_{A, T}=k_{A B}+k_{A G}+k_{A V}$, with respect to temperature. Brown, gray-blue, and dark magenta lines correspond to biocrude (B), gas (G), and volatiles (V), respectively. 

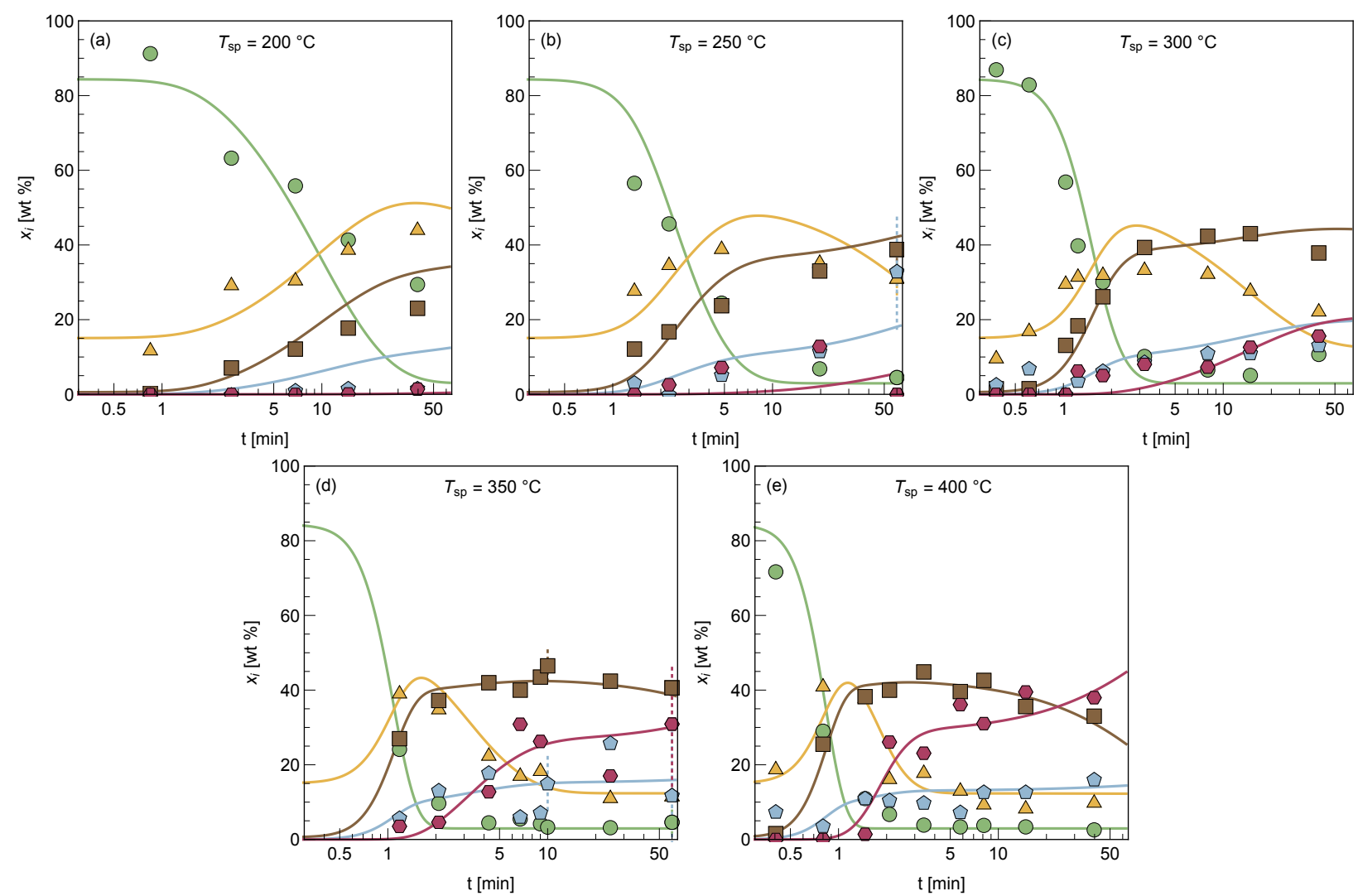

Figure 4: Model solutions (solid lines) and experimentally observed yields $\left(x_{i}\right)$ over time at different set-point temperatures $\left(T_{s p}\right)$ for solids (green circles), aqueous-phase products (gold triangles), biocrude (brown squares), gas (pale blue pentagons), and volatiles (purple hexagons). Dotted lines show standard deviation for selected experiments. 


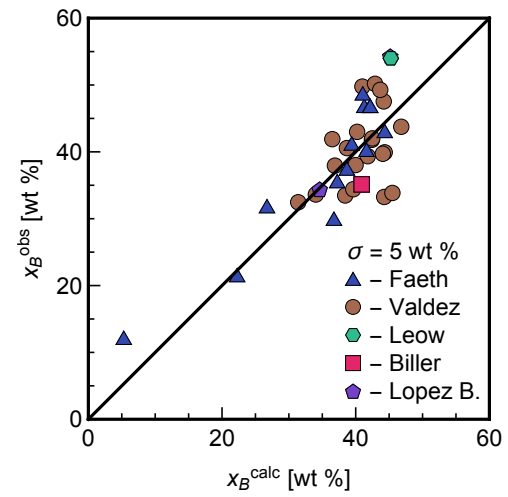

Figure 5: Parity plot of observed vs. calculated biocrude yields for data reported by Faeth et al. (2013), López Barreiro et al. (2013), Valdez et al. (2012), Biller and Ross (2011), and Leow et al. (2015). 


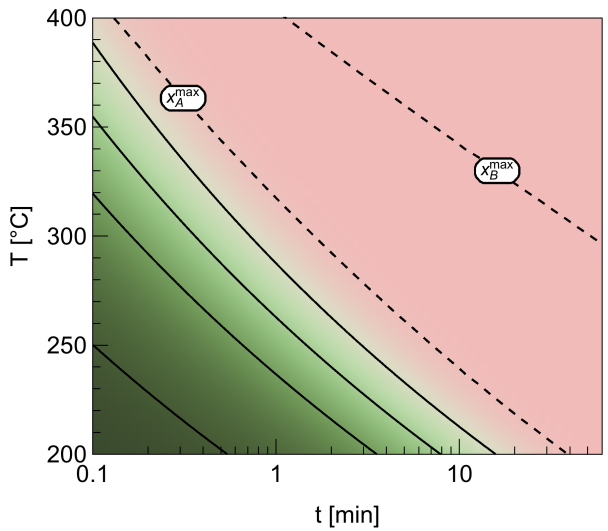

(a) Solids

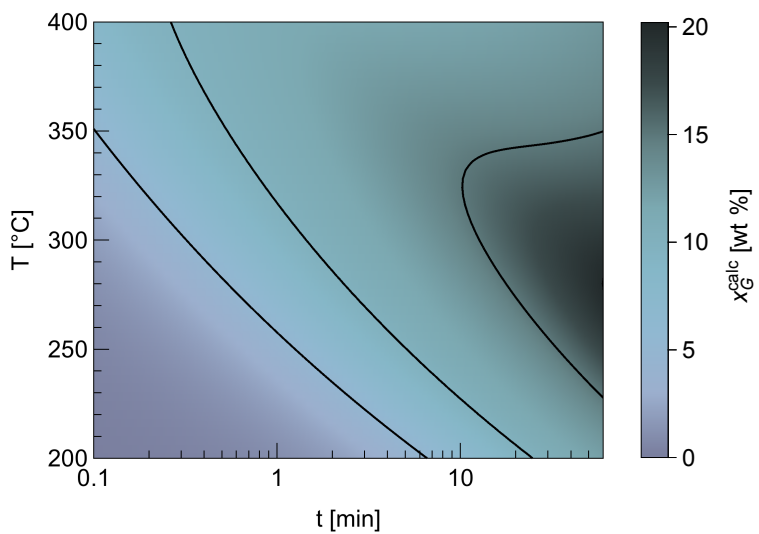

(c) Gases

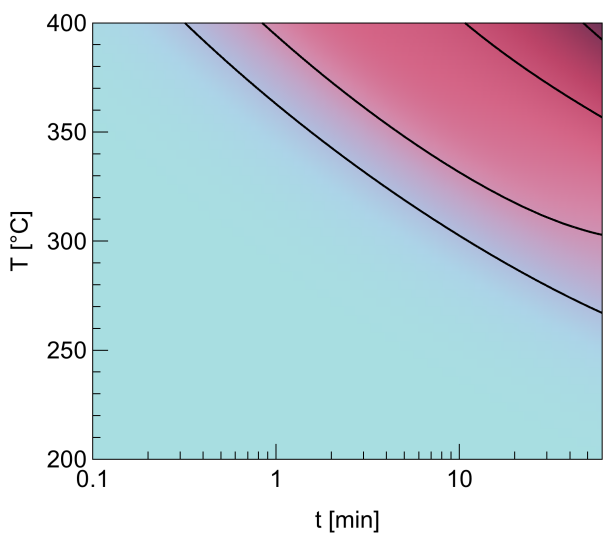

(e) Volatiles

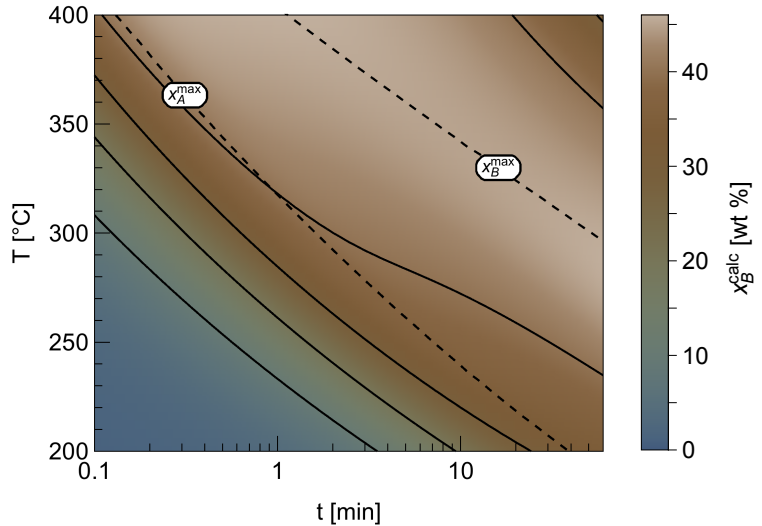

(b) Biocrude

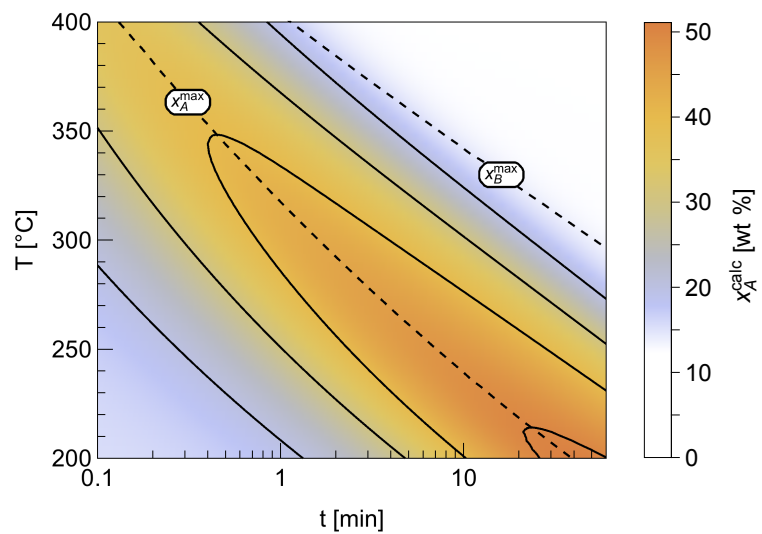

(d) Aqueous-phase products

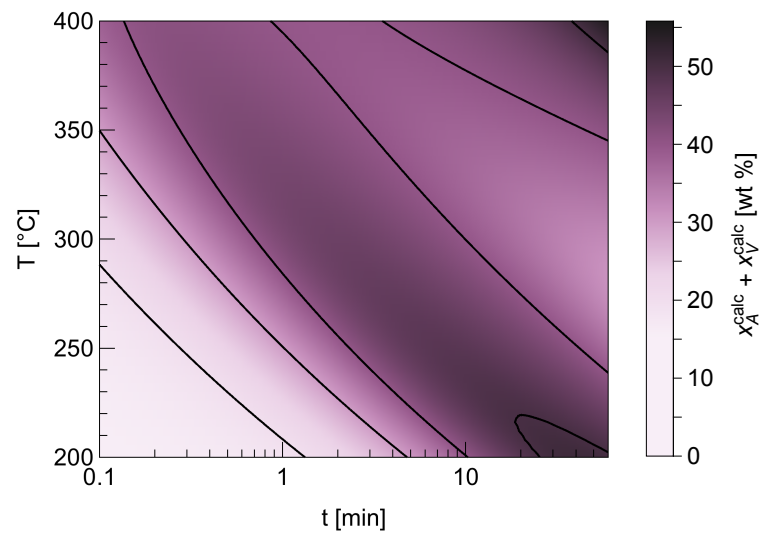

(f) Aqueous-phase + volatile products

Figure 6: (a) Solid, (b) biocrude, (c) gas, (d) aqueous-phase, (e) volatile, and (f) aqueous-phase and volatile product yields calculated as functions of time, $t$, and isothermal temperature, $T$. Solid black lines correspond to the yield contours marked by numbered ticks on the bar legend. Dashed lines show the maximum aqueous-phase product $\left(x_{A}^{\max }\right)$ and biocrude $\left(x_{B}^{\max }\right)$ yields at each temperature. 